\title{
O medo como mídia: estratégias de narração no jornalismo de O Globo
}

\author{
Leticia C. Matheus'
}

\begin{abstract}
Resumo: Este artigo apresenta o resultado de uma pesquisa que pretendeu evidenciar a comunicação jornalística como um processo dinàmico que solicita e reconfigura uma memória das sensações, tendo como elemento principal o medo. Destacou-se o medo como mediador da experiência cotidiana na cidade do Rio, a partir de narrativas apresentadas pelo jornal O Globo, na sua cobertura policial. Estudaram-se dois episódios: um assalto a uma estação do metrô, no qual morreu uma adolescente, e um ataque a uma universidade, do qual saiu ferida uma aluna, ambos em 2003. As coberturas desses dois casos se deram a partir de um conjunto de estratégias narrativas que forneccram um efeito de continuidade temporal e espacial ao fenònemo da violencia urbana. Deste modo, a leitura que se faz de cada novo crime se encontra em diálogo com parametros interpretativos fornecidos anteriormente pelo próprio jornal.
\end{abstract}

Palavras-chave: jornalismo - narrativa - sensacionalismo - memória - medo

\begin{abstract}
This article brings out the result of a research that intended to enlight the journalistic communication as a dynamic process which demands and reconfigures a memory of sensations, having fear as its basic element. Fear was highlihted as media for daily experience in Rio de Janeiro's city, by narratives presented through the newspaper O Globo, meanly through its police report. Two episodes were studied: an assault to a subway station, in which died a 14 year-old girl, and a bullet attack against an university, in which left wounded a student, both in 2003. These coverages were developed with some writing and editing strategies, which gave an effect of narrative continuum to the theme of urban violence. So, interpretations about each new crime are made by parameters previously given by the newspaper itself.
\end{abstract}

Keywords: journalism - narrative - sensacionalism - memory - fear

1 Doutoranda em Comunicaçào na UFF, com a pesquisa "Jornais centenátios e temporalidades", sob orientação da professora Marialva Barbosa. Bolsista da CAPES. Mestre em Comunicação pela UFF (2006), com a dissertação "Elos, temporalidades e narrativas: a experiencia contemporanca do medo no jornalismo de $O$ Giobo". Membro do núcleo de pesquisa do CNPq Midia, Memória e História. 
Compreender o jornalismo como um processo de mediação cultural é um tarefa difícil, sobretudo quando se está estudando a cobertura policial. No Rio de Janeiro, onde o tema da violência urbana adquiriu preponderância em quase todos os veículos, mais nitidamente os afetos são mobilizados em argumentos favoráveis ou contrários ao trabalho das mídias. Elas distorcem ou refletem a realidade? "A violência não é tão terrível, a mídia é que exagera" ou "a violência é terrivel, mas a mídia a banaliza." Essas são as duas posições extremas entre as quais oscila a opinião pública sobre o trabalho jornalístico e que acaba repercutindo nas análises acadêmicas. Foi tentando caminhar entre esses dois pólos que se deu a trajetória desta pesquisa.

Para começar, "violência urbana" não é um dado da realidade, mas o nome que se dá, simplisticamente, a um conjunto de problemas de natureza social, política, econômica e cultural. Esse conjunto é enfeixado em uma dada idéia de violência urbana, sobre a qual trabalham os jornais do estado do Rio, sobretudo na capital. Ou seja, não se trata da mesma interpretação do que seja violência quando se fala, por exemplo, do Iraque. Está excluída desse agenciamento narrativo (RICOEUR, 1994) sobre o Rio uma série de atos de violência criminal, como a doméstica, e, principalmente, estados estruturais de violência, como a desigualdade social, a privação do acesso aos serviços de saúde pública, habitação, entre outros, não classificados como violência pelos jornais. Sequer crimes passionais são integrados à categoria "violência urbana" - associada quase sempre a crimes e a ações de traficantes varejistas de drogas.

Duas conclusões marcaram esta pesquisa. A primeira diz respeito à estética sensacionalista, imediatamente associada à cobertura policial, sobretudo em jornais mais baratos, e que puderam ser verificadas também em jornais de referência, ditos "sérios". A segunda conclusão é algo bem próprio do que vem ocorrendo no Rio e que marca a experiência cotidiana da cidade a partir da sensação de medo. Percebeu-se que o medo tem não somente mediado a relação do leitor com seu jornal como tem funcionado também como mediador da relação do carioca com sua cidade.

\section{Sensacionalismo}

No Brasil, o adjetivo sensacionalista é atribuído a um conjunto de periódicos baratos, dedicados a um público com baixo grau de letramento, de modo a desqualificá-los a ambos (os jornais e seu público). Esses jornais se valem, como recurso de comunicação, de muitas fotografias, grandes e coloridas, textos curtos e simples, e muitas vezes títulos que simulam expressões orais usadas de modo descontraído no cotidiano do trabalhador. Frequentemente recorrem à comicidade para tratar de temas densos. Abordam o mundo do futebol, das celebridades 
e, sobretudo, histórias de crimes. Entretanto, o termo serve também de acusação contra jornais de referência, quando o público entende que eles foram parciais. Em ambos os casos, portanto, "sensacionalista" é algo pejorativo, usado para indicar uma suposta distorção de práticas jornalísticas ideais.

Dizer o que é ou não sensacionalista funciona como elemento de distinçào social. Em um pais pobre, ex-colônia, com baixo grau de escolaridade e letramento, o "bacharelismo ilustrado" funciona como signo de um dramático esforço de distinção das massas. (BARBOSA, 1996) Esse movimento se manifesta não somente no valor simbólico que um diploma e a erudição adquirem, como também em torno daquilo que se consome. E o campo da comunicação acaba reproduzindo, no ensino e na pesquisa, essa lógica preconceituosa.

Em 1971, o sensacionalismo já despertava interesse acadèmico na área, quando se deu a Semana de Estudos de Sensacionalismo na Universidade de São Paulo (USP). Aqueles anos 70 foram o periodo áureo de grandes jornais sensacionalistas, de tiragens média diária superiores a 100 mil exemplares (Notícias Populares, em São Paulo, e O Dia, no Rio). Na década seguinte, houve uma enorme proliferação de trabalhos acadèmicos sobre o assunto. Havia a impressào de que jornais e jornalistas tinham recorrido ao sensacionalismo como forma de sobrevivência em um período de cerceamento da liberdade de expressão. Já que política era tema proibido, o conteúdo de sexo, sangue e crime teria sido a alternativa. Portanto, depois do processo de abertura do regime militar na década de 80 , com a redemocratização do país, viveu-se um periodo de perplexidade frente à forte presença que o sensacionalismo mantinha. Se ele não era mais, em tese, necessário, por que esse jornalismo barato sobrevivia?

No fundo de tal perplexidade, havia imersa no senso comum uma crítica aos empresários de comunicação por uma sedução fácil do consumidor, com um suposto intuito ideológico de alienação da massa trabalhadora. Enebriado pelas sensações, o povo não desenvolveria interesse pela participaçào na vida política. Essa foi, durante anos, a visào corrente, mas o fato é que o sensacionalismo esteve ligado ao jornalismo no Brasil desde a virada do século XIX para o XX. As chamadas "notas sensacionais", junto com os folhetins, foram as grandes responsáveis pela popularização do jornalismo na antiga capital brasileira, graças às quais se formou um público leitor. Além disso, já na década de 20, apareceram na cidade jornais de enorme popularidade inteiramente destinados ao grotesco, ao inusitado, ao desvio, à quebra de padrōes de uma dada normalidade (Manhã e Crítica). (Idem, ibidem)

Se pensado de uma maneira mais ampla, tal qual uma categoria estética que se apóia nas sensações físicas, com modos próprios de narrar, sejam eles por uma linguagem hiperbólica ou por um apelo ao imaginário popular, o sensacionalismo pode ser encontrado em várias instâncias da comunicação social. Hoje, depois de 
uma ampla produção acadêmica, da influência de conceitos como "circularidade da cultura" (BAHKTIN, 1999), dos estudos culturais e da idéia de que a cultura popular invade e sobrevive na massiva (MARTÍN-BARBERO, 2001), não é mais possível considerar o gosto pelo sensacional como algo determinado por classe ou por nível de escolaridade. $O$ fascínio diante da morte rompe todas as manhãs a camada de verniz cultural que segmentaria, em tese, o mercado em um gosto "popular" e um gosto de elite. (ANGRIMANI, 1994)

Não se pretende afirmar com isso que as sensibilidades sejam homogêneas e que não estejam também submetidas aos processos históricos. Mas dai a dizer que somente as classes menos favorecidas, mais iletradas, sejam mobilizadas pelas sensações é algo bem diferente.

\section{A cobertura policial}

Para verificar a presença do sensacional e analisar a narratividade acerca da violência, recorreu-se a um jornal de referência, O Globo, em 2003, ano bastante pobre do ponto de vista do noticiário. Não houve eleições, nem Olimpíadas, nem Copa do Mundo de futebol, nem grandes catástrofes. A única grande cobertura naquele ano foi a invasão do Iraque pelos Estados Unidos em 20 de março. Porém, este acontecimento era tratado, evidentemente, na editoria "Internacional". À editoria local, "Grande Rio", faltava noticiário capaz de prender a atenção do leitor, com exceção, é claro, dos crimes.

Um dos mais lidos do Rio desde a década de 70, O Globo tinha, em 2003, uma circulação média de 253.410 exemplares por dia. Além de atingir as classes mais favorecidas, moradoras das áreas nobres do Rio, é um dos jornais brasileiros lidos nas instâncias federais de governo. Apesar de seu poder mercadológico e simbólico, O Globo assistia naquele ano à contração do mercado de impressos. Os diários brasileiros vinham sofrendo sucessivas quedas de tiragem, tempo médio dedicado à leitura e investimento publicitário nos três anos anteriores. O Globo, que variava entre a quarta e a segunda posição entre os maiores jornais do país, já acumulava uma queda de $14,5 \%$, de 2001 a 2003, na sua circulação. Esse dádo não configura prova, mas pode ser indicativo da necessidade de apelar às sensações para garantir o pacto com o leitor.

Naquele ano, o jornal trouxe chamadas de primeira página sobre violência em $76,7 \%$ dos dias. Mas o que mais chamou a atenção foi a presença, explícita ou não, de uma sensação em particular: o medo. Ele apareceu não somente como protagonista das histórias, com uma presença difusa como se emergisse ao acaso, como também como uma espécie de elo entre diferentes notícias, construindo um continuum narrativo sobre a violência. Para aprofundar essas hipóteses, focou-se especificamente nas coberturas de dois episódios ocorridos na cidade naquele ano 
e separados no tempo por 41 dias, porém unidos narrativamente no jornal: um assalto a uma estação do metrô e um ataque a tiros a uma universidade.

Eram três e meia da tarde de uma terça-feira. A psicóloga Cleide do Prado Ribeiro esperava a filha em uma estação do metrô. As duas iriam comprar um vestido para que a menina fosse a uma festa no final de semana. Era a primeira vez que deixava a única filha, de 14 anos, sair sozinha e imaginou que o metrô fosse o meio mais seguro. Gabriela, a filha, só teria que viajar um pequeno trecho, mas a filha estava demorando demais. Então Cleide ouviu comentários a sua volta de que uma estação fora assaltada. Apreensiva, ligou para o marido e pediu que ele fosse procurar Gabriela. Carlos Ribeiro correu até a outra estação e não encontrou a menina, mas seus óculos caídos no chão, junto à escada. A filha já estava morta.

A história foi contada com forte carga melodramática, em detalhes, no dia 26 de março, desencadeando uma longa cobertura. Exatamente 41 dias depois, outra jovem foi atingida por um disparo de arma de fogo. Desta vez, o crime ocorreu em um campiss universitário, quando alguns traficantes teriam ordenado o fechamento da instituição em represália a uma suposta extorsão realizada por policiais militares. Se a direção se negasse a obedecer, a universidade seria alvejada. Tendo ela obedecido ou não, tendo os disparos sido feitos de dentro da universidade ou não, o fato é que, na manhã de 5 de majo de 2003, balas cruzaram o campus e uma delas se alojou na coluna cervical da estudante Luciana de Novaes, que ficou tetraplégica. Essas duas histórias receberam farta cobertura do jornal durante várias semanas.

Mas elas tiveram muito mais em comum do que o fato de tratarem de vitimas de balas perdidas. Houve pelo menos três elos narrativos / editoriais. $O$ primeiro foi o relato da visita da mãe de Gabriela, ao hospital onde J_uciana estava internada. O segundo foi o uso de uma foto na primeira página, em que os amigos de faculdade de Luciana simulavam uma pomba da paz com as mãos, mesmo gesto feito por Gabriela na fotografia que serviu de rubrica para seu próprio caso. $O$ terceiro ponto em comum a Polícia Civil se encarregou de fornecer, ao afirmar que um dos apontados como responsável pelo disparo que atingiu a estudante seria o mesmo suspeito de comandar o assalto ao metró.

Ou seja, o caso Luciana se apresentou como uma espécie de continuação do caso Gabriela que, por sua vez, não era algo inédito. Além da atmosfera belicosa que a comparação com a guerra do Iraque trazia "A guerra do Rio", como foi rotulada, a cobertura do caso Gabriela falava em "mais unna vítima" e fazia referência a uma série de outros episódios ocorridos naquele ano, e mesmo em anos anteriores, como outros assaltos ao metró e outras situaçōes de vulnerabilidade de jovens. Optou-se por não detalhar aqui os inúmeros exemplos, levantados durante a pesquisa, que fornecem a sensação de continuidade entre essas duas coberturas e outras daquele ano. O foco será isso que se pode chamar de elos "mais profundos, 
que inserem essas histórias em um continuum de uma grande narrativa da violência e que, por sua vez, conformam o sentido dessa idéia de violência. Eles também são três.

O primeiro é a inserção dessas histórias a um fluxo sensacional. Nele, habitam figuras arquetípicas, personagens que funcionam como signos que emergem em diferentes contextos. Além disso, apóiam-se no imaginário popular, por meio de enredos que atravessam gerações, seja pela comunicação oral, sejam atualizados pelos meios de comunicação de massa. É possivel afirmar que as duas coberturas foram configuradas de modo melodramático, principalmente sob os pilares da dor e do medo, com personagens polarizados entre Bem e Mal. Com isso, uma certa estrutura melodramática acaba servindo de parâmetro interpretativo da relação do cidadão com sua cidade e seu cotidiano.

Gabriela e Luciana foram tratadas como arquétipos da vítima do melodrama, atingidas pelo Destino inexorável e cruel. Suas biografias foram reconstituídas, seus sonhos narrados, a dor de suas famílias explorada à exaustão. É como se, para compreender essas histórias, fosse necessário um repertório prévio capaz de ajudar o leitor a identificar mocinhos e vilões. O mesmo ocorre com o próprio repórter que muitas vezes recorre aos arquivos do jornal para verificar como casos parecidos foram apurados e contados anteriormente. Não se pode esquecer que o jornalista vivencia uma profissão com fortes traços de tradição, sobretudo na reportagem policial. Nesse sentido, os modos de narrar servem como receituário e são atualizados a cada nova oportunidade. O leitor participa desse processo, com um conjunto de expectativas acerca do que ler naquelas páginas, o que Chartier (1996) chamaria de pacto ou protocolo de leitura.

O segundo elo foi descoberto por acaso. Inspirada na análise que Ricoeur (1995) faz de Mrs. Dalloway (Virginia Woolf), A Montanha Mágica (Thomas Mann) and Em Busca do Tempo Perdido (Marcel Proust), procuraram-se as estruturas temporais das duas coberturas e se percebeu que a grande ameaça, em ambos os casos, aquilo que se temia, confundia-se com uma sensação de paralisia. Ou seja, a experiência temporal da cidade se moldaram narrativamente nessas reportagens a partir da percepção de suspensão do tempo. Os corpos das duas jovens funcionaram como metáforas da cidade. Elas tiveram a trajetória de suas vidas interceptadas pela crescente aceleração (entendida na Modernidade como emblema de eficiência) da ação dos criminosos (em oposição à apatia das autoridades).

No caso Gabriela, enquanto a mãe aguardava apreensiva em uma estação do metrô, na outra, a filha vivia a premência da morte, em um fluxo de acontecimentos velożes e simultâneos. Essa separação entre duas temporalidades foi inclusive marcada por um entretítulo que impõe uma fronteira na mancha gráfica no texto principal do primeiro dia da cobertura. O religamento entre elas se dá quando a personagem de um dos ambientes invade o outro, ou seja, quando o tempo da espera vai ao encontro do tempo da morte. Carlos, pai de Gabriela, resolve ir até a estação 
onde a filha deveria ter embarcado. Lá encontra apenas os óculos da filha caidos na escada. Eles condensam a metonímia de Gabriela e a metáfora da morte.

Já Luciana pensava em transferir a matrícula para outro campus por causa dos tiroteios constantes na favela próxima. Ou seja, o medo foi subestimado e o tempo da decisão foi mais lento do que o tempo do crime. Em um box, um colega de faculdade diz que naquela manhã os alunos ouviram disparos nas proximidades, mas que não se importaram porque isso era comum. Quando repararam que os tiros eram em direção ao campus, saíram correndo. Luciana nào teve tempo e caiu ensangüentada. O tempo da bala é mais veloz do que o tempo de correr. Ou seja, mais uma vez se articulam a agilidade do crime contra a lentidão da ordem.

Mais importante, porém, foi perceber que o jornal trabalhou narrativamente com duas temporalidades, produzindo uma idéia de disseminação temporal do medo: uma linear, outra cíclica. Enquanto narrava o tempo histórico, o vivido, como linear progressivo, ou seja, como uma sucessão de acontecimentos que se seguem uns depois dos outros, o jornal também produzia um efeito de repetição. O resultado disso, ao lê-lo, foi a percepção de a violência e o caos na cidade se tornarem progressivamente piores, com a acentuação da barbárie. Ao mesmo tempo, a idéia de que episódios semelhantes se repetiam, de forma cíclica, criava uma angústia permanente em relação ao futuro. Ou seja, nessas narrativas, "crime", "medo" e "violência" se tornaram entidades abstratas, a-históricas, sem sujeitos, capazes de brotar sem que ninguém fosse responsável, capturando vítimas ao acaso. Desses jogos narrativos com o tempo se produziu uma cobertura apoiada no pânico. E, diante do medo, quem sai ganhando é o próprio jornal, que se faz simbolicamente necessário. Se a violência brota ao acaso, é preciso racionalizá-la e o jornal é vendido como uma espécie de esforço de "domenticação" simbólica da morte e do medo.

\section{Memória das sensações}

O terceiro elo "profundo" entre essas coberturas é a memória do medo. Recorreu-se ao conceito de Ricoeur (1994) de tríplice mímese para fragmentar o processo comunicacional, no intuito de melhor analisá-lo. Se um texto qualquer não é portador de significado mas um lugar de convergência desse processo comunicacional, ou seja, um mediador, jamais se poderia afirmar que O Globo gerou pânico. Isso não impede, por outro lado, que se diga que o periódico acionou una memória do medo para fazer com que sua mensagem fosse compreendida. Como ele acionou essa memória e no que ela consistia?

Considerando que a mímese I, para Ricoeur, é a pré-compreensão do mundo, escolheu-se entendê-la ora como memória coletiva (HALBWACHS, 1990), ora como imaginário (PLATAGEAN, 1990). As coberturas jamais poderiam ter sido 
compreendidas se o leitor não tivesse completado seu sentido (mímese III) a partir de uma idéia de violência extraída do seu imaginário. Esse leitor (empírico ou pressuposto) interpretou essas reportagens ao atualizar uma certa memória do medo.

É preciso deixar claro que não houve pretensão de dar conta da totalidade dos temores possíveis implicados nas narrativas desse jornal. Nem de buscar aqueles que representassem os anseios de toda a sociedade carioca, mas apenas alguns medos de determinado público que compartilhou a leitura de $O$ Globo. Além disso, não interessaram os medos que as pessoas pudessem cultivar individualmente, mas apenas os medos coletivos que precisavam ser acionados para tornar essas reportagens inteligiveis, fosse para se identificar com a vitimização de quem temia, fosse para criticar o que pode haver de cinismo nessa postura.

Partiu-se do pressuposto que os sentimentos constituem matéria social e histórica. Ou seja, que as experiências e as atitudes frente aos medos podem variar tanto ao longo do tempo quanto em relação a diferentes grupos sociais. Deste modo, o medo pode funcionar como importante instrumento de interpretação e intervenção histórica. Olhar para o que as pessoas temem em um determinado momento e lugar ajuda a entender o que elas vivem, como se comportam. (DELUMEAU, 1996) Na disputa pelas interpretações dos sentimentos sentidos coletivamente, os medos midiáticos figurados nas notícias sensacionais são fundamentais para ler os diálogos que se estabelecem entre as pessoas e seu tempo.

Delumeau (ibidem) afirma que as coletividades estão comprometidas em um diálogo permanente com o medo, mesmo com aqueles que podem parecer simples e irreais. Alguns medos são objetivados em determinados momentos, como se esperassem a oportunidade para emergir de um subsolo inconsciente. É evidente que existem medos próprios de determinados momentos históricos, mas há outros que persistem na longa duração. Dentre estes, alguns foram objetivados em situações e personagens concretos nessas coberturas, fornecendo imagem a algo inconsciente ou inconfessável.

$\mathrm{O}$ medo da morte é o primeiro e mais fundamental deles. Mas medo da morte de quem? Em primeiro lugar, está em jogo a morte de si. Sob esse aspecto, pode-se dizer que as reportagens sensacionais de certa forma trazem alivio ao oferecerem o consumo de uma morte simbólica. Nesse sentido, a mídia assume um importante papel na Modernidade ao se tornar o lugar da encenação e cerimônia de morte, em um mundo cada vez mais ascético, que bane cada vez mais a morte para as coxias da vida social. (SCLIAR, 2003, VOVELLE, 1987, ARIÈS, 1977) Mas as coberturas dos casos Luciana e Gabriela também encenaram o medo da morte do outro. E esse outro que morre é o objeto amado, geralmente um filho.

O periódico seduziu seu público a partir do medo de se deixar um filho começar a dar seus primeiros passos sozinhos rumo à maturidade. $O$ jornal destacou que Gabriela estava indo comprar roupas novas para uma festa e que insistia com 
a mãe que já podia usar saltos altos. A família de Luciana contou que ela é o xodó da casa, a caçula. Embora fosse na ocasião uma adolescente de 19 anos cursando a faculdade de enfermagem, o jornal explorou o medo que os pais têm de deixar os filhos sozinhos na rua, mais uma vez entrelaçando o enredo com o caso Gabriela. Além disso, as escolas primárias e ginasiais começaram a cancelar as aulas ao receberem telefonemas ameaçadores, como o que teria recebido a universidade onde Luciana estudava. O fato é que o medo generealizado serviu tanto para que bandidos tentassem extorquir donos das escolas quanto para alunos passarem trotes e terem um dia de folga.

No quinto dia da cobertura do caso Luciana, o medo, tornado protagonista, já alcançava ares de histeria coletiva. "Cultura do medo se espalha no Rio", dizia a manchete de nove de maio. A reportagem principal que dá origem à manchete foi montada a partir de diferentes fatos ocorridos naquele dia e que não tinham necessariamente relação entre si a não ser pelo medo envolvido. Havia fotografias de até um ano atrás.

O segundo desses medos que povoam o imaginário de uma elite carioca e no qual O Globo ancorou essas coberturas é o medo da alteridade produzida a partir de um mecanismo de norma e desvio. (FOUCAULT, 1995) O "outro", no caso do Rio e que é reificado nessas reportagens, não é um estrangeiro, mas uma parte da população que tem sua "marginalidade" reatualizada permanentemente. Já foi o capoeira ${ }^{2}$, o sambista, o morador do cortiço, identificado como disseminador de doenças na cidade ${ }^{3}$, e mais recentemente o funkeiro, o traficante varejista de drogas que se esconde e/ou mora nas favelas. Ou seja, são personagens perseguidos pela polícia e/ou estigmatizados.

Batista (2003) fala do medo como instrumento de reforço das fronteiras simbólicas dentro da cidade do Rio e da produção de um grande "outro" que se deveria temer. Sua principal hipótese é que o medo se torna determinante para a adoção de medidas repressivas. Rondelli (2000) já se refereria ao mecanismo de agendamento das politicas públicas de modo a proteger aqueles que são caracterizados como ameaçados. Lembre-se que no dia seguinte ao ataque à universidade, o jornal destacou que a Polícia Militar estava "vasculhando" o Morro do Turano. Três dias depois da morte de Gabriela, a polícia também tinha "vasculhado" (o verbo usado foi o mesmo) a Favela Paula Ramos. Houve tiroteio e o tráfego de um importante túnel fechado. Medidas espetaculares de governo para demandas espetaculares do público.

Ou seja, o medo funciona também como medida de controle / contenção social. No Globo, ele é articulado como fruto dos pavores das elites que experj-

2 Capoeira é como eram chamados os praticantes da capoein, arte marcial brasileira de origem africana. e que se associavam em gangues e cram contratados por politicos e comerciantes como guarda-costas e seguranças no inicio na virada do século $X I X$ para o $X X$.

31.600 casas, a maioria cortiços, foram demolidas entre 1903 c 1906 é a populaçào se refugiou nos morros próximos, formando as primciras favelas no Rio. 
mentam a sensação de vulnerabilidade justamente devido a sua condição social. $E$ assim se encena nas páginas do jornal a luta pela posição da vítima. $O$ jornal torna-se campo de batalha.

Por ele, se dá parte dos processos de estigmatização da cultura popular, principalmente por meio da produção do desvio. É devido a um duplo mecanismo - a criminalização de comportamentos populares (CHALHOUB, 2005) e a estigmatização do espaço, a favela - que prevalece um imaginário acerca do Rio de Janeiro que pré-configura o que apareceu nas páginas de O Globo: a cidade quilombada (BATISTA, 2003), aquela que fica nas favelas, de onde teriam saído os disparos contra a universidade, e onde se esconde o assaltante do metrô. Tanto o metrô quanto a universidade, os lugares onde se deram esses crimes, são narrados como símbolos de uma cidade idealizada, enquanto a favela é seu símbolo antagônico.

A alteridade encenada no Rio passa também por uma questão étnica. Não se pode esquecer que tanto a história de Gabriela quanto de Luciana têm como vilão o mesmo Carlos Eduardo Soares Ramalho, cujo vulgo é Nego. O curioso é que o argumento usado pela polícia para supor que o criminoso fosse o mesmo nos dois casos foi a semelhança na sua descrição física, mas a única característica citada foi o fato de ele ser negro. No melodrama midiático da chamada "violência urbana", os papéis de vítimas são sempre dedicados a pessoas que se identificam como brancas.

Batista (ibidem) chega a afirmar que a história dos brasileiros negros é contada pelos jornais por meio das fichas policiais. Ela estuda o impacto que a revolta de um grupo de escravos negros muçulmanos (Revolta Malê), no estado da Bahia em 1835, teve no imaginário carioca acerca de uma iminente revolta negra, principalmente entre os anos 1830 e 1870. A partir daí o governo lançou um projeto eugenista de "branqueamento" populacional por meio da imigração de trabalhadores europeus e de miscigenação. Pretendia-se "clarear" a população de modo a prepará-la para uma passagem "tranquila" de uma sociedade de castas para uma sociedade de classes. Ou seja, havia o pavor de uma inversão racial depois da Abolição. Além disso, estava-se formando pela primeira vez o sentimento de nacionalidade brasileira, e, do ponto de vista das elites, ela não poderia se basear em uma identidade não-branca. (AZEVEDO, 1987)

Passados tantos anos, os principais "clientes" do aparelho repressivo, dos cárceres e dos cemitérios clandestinos ou não são jovens de até 19 anos, negros, principais vítimas da violência (ZALUAR, 2004), ao contrário do que pode parecer ao se ler O Globo. Diferentemente de uma expectativa de ver a morte domada, saneada, morre-se no Rio cada vez mais de causas externas violentas. E quem é morto é justamente essa faixa populacional jovem e economicamente ativa.

O temor da alteridade se configura nessas narrativas também em torno do fantasma das revoltas populares. O bandido só é bandido se for um agente da 
desordem, espécie de eufemismo para revolta. O critério para que esse bandido participe de um enredo policial sob o tema da violência urbana é fazer parte de uma massa percebida como perigosa. $\mathrm{E}$ a ordem, no Brasil, representa um conceito-chave na formação da República, criada a partir de ideais positivistas.

Segundo O Globo, a violência teria tido um passado ingênuo até a década de 80 e teria se profissionalizado e se tornado mais cruel. É possivel identificar vátios personagens que já foram alvo dessa demanda por contenção, aqueles que representam o perigo (normalmente o pobre e desempregado), e que passam assim a ser identificado com o elemento criminoso. Como diz Borges (2005), no Brasil, a questão social é tratada tradicionalmente como questão policial, tanto no campo quanto nas cidades. Cria-se dessa forma uma espécie de "inimigo interno". A contenção social pode se dar não somente pela violência mas também por mecanismos simbólicos, tal como a estigmatização. Elias e Scotson (2000) descrevem esse processo a partir do desenvolvimento do carisma coletivo, ou do auto-elogio de um grupo, o que implica a depreciação do outro. Só que nessas narrativas analisadas, esse processo se dá por auto-vitimização. Dificilmente a população pobre, moradora das favelas, ou mesmo o pequeno traficante varejista, são narrados como vítimas de alguma coisa, embora seja duplamente alvo, tanto das medidas repressivas das autoridades, quanto da brutalidade do crime.

Ao se analisar jornais fluminenses no século XX, encontrou-se a associação do medo à desordem em diferentes temas, lugares e personagens. Nas primeiras décadas, os periódicos expressavam a preocupação com "civilização" da cidade e o esforço de apagamento de qualquer característica que fizesse lembrar o passado colonial, inserindo o Rio na Modernidade a qualquer custo. (BARBOSA, 1996) $\mathrm{Na}$ década de 50 , já no jornal O Globo, havia, por exemplo, "o inquietante problema comunista" (O Globo, 11/03/54), e a apreensão em relação às atividades subversivas, às greves, às manifestações, ao iminente caos político. Na década seguinte, o risco dos "subversivos" se intensifica continua na década de 70. Ganham destaque nessas duas décadas, entretanto, outros tipos de anseios, como a falta de habilidade dos policiais em desvendar os crimes.

Desde a década de 50 , encontram-se criticas em relação à arbitrariedade dos policiais na condução de casos políticos. Até então, as reportagens policiais eran tratadas com forte carga de suspense, enfatizando-se o fato de o periódico estar contribuindo para desvendar mistérios. Essa situação iria se inverter na década de 60 , quando a crítica aos casos políticos silencia e os jornais se voltam para a crítica a ação da polícia contra a violência criminal. Isso pode ser indício da crescente adoção de um discurso por demanda por repressão como indica a matéria: Ou: "Policiamento ostensivo mais eficiente" (O Globo, 08/01/67, p. 8). Ou ainda: "Farão jus os homens da polícia aos impostos pagos pelo povo" (O Globo, 14/01/67, p. 13).

Ilustra essa tendência repressora o fato de as favelas, por exemplo, serem cada vez mais destacadas como lugares perigosos, que precisam ser contidos, além 
da Baixada Fluminense. "Mais uma mulher apareceu degolada em Nova Iguaçu" (O Globo, 04/01/67). "Lei dura contra crime na Baixada" (O Globo, 05/01/67). "Clima de rebelião no morro do Borel. Todo desconhecido que chega ao morro do Borel é olhado com desconfiança e hostilidade. Os favelados aguardam, em clima de rebelião, a execução do despejo determinado pelo juiz..." (O Globo, 06/06/60, $1^{a}$ página)

Essa multiplicidade de objetos de temor indica que, a cada época, dependendo do contexto político, econômico, social e cultural, as objetivações do medo vão mudando - uma hora o capoeira, na outra o morador da favela, mais adiante o traficante -, enquanto outras persistem, mas os meios de comunicação estão sempre lá, distribuindo os papéis de quem deve temer, o que e como. (BATISTA, 2003)

\section{Considerações finais}

Esta pesquisa mostrou que o medo midiático tem funcionado como vínculo mnemônico entre múltiplas histórias que compõem uma grande narrativa do medo no Rio de Janeiro e que consolidam uma dada idéia do que seja a violência urbana. Assim, o medo tem servido como importante mediador da experiência contemporânea naquela cidade. Mais importante, porém, foi perceber que a referencialidade das notícias vai muito além dos fatos. Ancora-se a narratividade jornalística também no imaginário, nas sensações e concepções de mundo profundamente arraigadas e muitas vezes inconfessáveis. Ou seja, o jornal precisa se apropriar também do imaginário para se fazer inteligivel e tornar sua leitura necessária. Para reverberar ansiedades e depois oferecer conforto simbólico. Além disso, o medo, para quem teme, pode oferecer tanto conforto quanto bons argumentos para demandas repressivas de parte da sociedade.

Este estudo ajudou a perceber que a relação entre o que as pessoas fazem na vida e sua representação midiática, por exemplo, jornalística, não se explica por uma simples relação linear de causa e efeito, nem como espelho neutro. Os moradores do Rio não entraram em pânico por causa de O Globo, mas tiveram oportunidade de ler nessas páginas um punhado de medos conscientes/ inconscientes e/ou inconfessáveis que, por sua vez, ajudaram a moldar a interpretação dessas duas coberturas bem como o sentido geral da violência urbana. É nesse diálogo permenante entre os jornais e o público que se constrói o sentido daquilo que está sendo narrado e no qual os jornais se fazem necessários. Neste caso, o mediador dessa relação foi o medo. 


\section{Referências bibliográficas}

ARIĖS, Philippe. História da morte no Ocidente. Rio de Janeiro: Livraria Francisco Alves Editora, 1977, p. 15-180.

ANGRIMANI, Danilo. Espreme que sai sangue. São Paulo: Summus Editorial, 1994.

AZEVEDO, Celia Maria Marinho de. Onda negra, medo branco. O negro no imaginário das elites - século XIX. São Paulo: Editora Paz e Terrra S.A., 1987.

BAKHTIN, Mikhail. A cultura popular na ldade Média e no Renascimento: o contexto de François Rabelais. São Paulo: Hucitec, 1999.

BARBOSA, Marialva C. Imprensa, poder epúblico (Os diários do Rio de Janeiro - 1880-1920). Tese de doutorado em História. Universidade Federal Fluminense, Niterói,1996.

BATISTA, Vera Malaguti. O medo na cidade do Rio de Janeiro. Dois tempos de uma história. Rio de Janeiro: Editora Revan Ltda, 2003.

BORGES, Wilson Couto. Midia, violencia e conjuntura política: a presença dos militares no Rio de Janeiro. Dissertação de mestrado em Ciencia Politica pelo ICHF/UFF, 2005.

CHALHOUB, Sidney. Trabalho, lar e botequim. Campinas (SP): Editora Unicamp, 2005.

CHARTIER, Roger. Práticas de Leitura. São Paulo: Estação Liberdade, 1996.

DELUMEAU, Jean. História do medo do Ocidente - 1300-1800, uma cidade sitiada. São Paulo: Companhia das Letras, 1996.

ELIAS, Norbert e SCOTSON, John L. Os estabelecidos e os ontsiders. Rio de Janeiro: Jorge Zahar Editor, 2000.

FOUCAULT, Michel. Vigiar eptinir: História da violência nas prisões. Petrópolis (RJ): Editora Vozes, 1995.

HALBWACHS, Maurice. A memória coletiva. São Paulo: Edições Vértice, Editora Revista dos Tribunais Ltta, 1990.

MARTIN-BARBERO, Jesús. Dos meios às mediaçoes. Comunicação, Cultura e Hegemonia. Rio de Janeiro: Editora UFRJ, 2001.

PATLAGEAN, Evelyne. "A história do imaginário". In LE GOFF, Jacques (org.). A nova bistória. Coimbra (Portugal): Livraria Almedina, 1990.

RICOEUR, Paul. Tempo e Narrativa. Campinas (SP): Papirus Editora, 1994, tomo I.

Tempo e Narrativa. Campinas (SP): Papirus Editora, 1995, tomo 11.

RONDELLLI, Elizabeth. "Imagens da violência e práticas discursivas". In: PEREIRA, Carlos Alberto Messeder et elii (orgs.). Linguagens da l'iolência. Rio de Janeiro: Rocco, 2000, p. 144-162.

SClIIAR, Moacyr. "O Renascimento da Melancolia". In: Saturno nos Trópicos. 
A Melancolia européia chega ao Brasil. São Paulo, Companhia das Letras, 2003, primeira parte, p. 5-166.

VOVELLE, Michel. "Sobre a morte". In: Ideologia e Mentalidades. São Paulo, Brasiliense, 1987, p. 127-150.

ZALUAR, Alba. Integrąãa perversa: pobreza e tráfico de drogas. Rio de Janeiro: Editora FGV, 2004.

\section{Para ter acesso à bibliografia completa da pesquisa:}

http://www.bdtd.ndc.uff.br/tde_busca/arquivo.php?codArquivo=905

\section{Fontes:}

ASSOCIAÇÃO NACIONAL DE JORNAIS. Dados. Disponível em: www.anj.org.br. Ùltimo acesso em: 21/01/2006.

ASSOCIAÇÃO NACIONAL DE JORNAIS. Dados. Disponível em: www.anj.org.br. Último acesso em: 21/01/2006.

O Globo: cobertura referente ao caso Gabriela nas edições de 26 a 30 de março de 2003;

cobertura referente ao caso Luciana nas edições de 6 a 10 de maio de 2003;

edições de maio, junho, novembro e dezembro de 1954;

edições de junho de 1960;

edições janeiro e agosto de 1967;

edições de setembro de 1969;

edições de março de 1977;

reportagem do dia $1^{\circ}$ de maio de 2005. p. 19, $2^{a}$ edição;

caderno especial do dia 30 de julho de 2005.

Exposição "80 anos de História nas páginas do Globo", no CCBB, 2005. 